\title{
Comparison of body fat using various bioelectrical impedance analyzers in university students
}

\author{
Petr Kutá ć,* $^{1,}$ and Miroslav Kopecký ${ }^{2}$ \\ ${ }^{1}$ Human Motion Diagnostics Center, University of Ostrava, Ostrava, Czech Republic; and ${ }^{2}$ Faculty of Health Sciences, \\ Palacký University Olomouc, Olomouc, Czech Republic
}

Copyright: (C) 2015 P. Kutáč and M. Kopecký. This is an open access article licensed under the Creative Commons Attribution License (http://creativecommons.org/licenses/by/4.0/).

\begin{abstract}
Background: At present, the portfolio of devices using the bioelectrical impedance (BIA) method is continuously expanding as a result of the wide use of this method in the field as measurements by this method are fast and staff training is simple and reasonably priced. Nonetheless, the problem is that despite using the same method, bioimpedance analyzers can differ in many parameters. They use different electric current frequencies, a different number of electrodes and the electric current may be conducted through different parts of the body. Objective: The main objective of the study is to compare and evaluate the differences of values of the analysis of the body fat of university students measured by BIA analyzers that differ in the applied electric current frequency, number of electrodes and flow of the electric current through the individual body parts. Methods: The research included 125 participants (70 male and 55 female). The measurements were taken by the following analyzers: Tanita 418 MA, InBody 720, InBody R20 and Omron BF 300. Results: The differences in the mean values of the body fat representation between the used analyzers in men ranged from 0.1 to $3.4 \%$ and from 0.0 to $2.4 \mathrm{~kg}$, in women from 0.5 to $6.5 \%$ and from 0.4 to $3.8 \mathrm{~kg}$ in relation to the used analyzer. Conclusions: In men with regular physical activity, the values measured by InBody R20 were statistically and practically different. The analyzer measured higher values that other analyzers. In women, there were statistically and practically significant differences in the values measured by Omron BF 300 . This analyzer measured lower values than other analyzers.
\end{abstract}

Keywords: adipose tissue, young adult, single frequency analyzer, multi frequency analyzer, Bland-Altman analysis

\section{Introduction}

Nowadays, the evaluation of body composition is commonly used for the assessment of the medical condition of an individual, the level of nutrition and physical fitness (McArdle, Katch, \& Katch, 2007). In medicine, it is used as a part of diagnostics in diabetics, nephrology, obesity science and osteology (Parikh et al., 2004; Pluijm et al., 2001; Pravn et al., 1999). In sports, it facilitates efficient management of the training process. On the basis of the body composition evaluation, we can to some extent determine the level of readiness of the athlete's organism for strain. By monitoring changes in the body composition, we can also evaluate the effect of physical exercise on the athlete's organism and asses its adequacy (Bauer, Pivarnik, Fornetti, Jallo, \& Nassar, 2005; Green, Pivarnik, Carrier, \& Womack,

\footnotetext{
* Address for correspondence: Petr Kutáč, Human Motion Diagnostics Center, University of Ostrava, Varenska 40a, 70200 Ostrava 1, Czech Republic. E-mail: petr.kutac@osu.cz
}

2006; Quinney et al., 2008; Rahimi, 2006; Sanchez, Sanz, \& Zabala, 2007) in medicine, it helps us assess the effect of the applied treatment (such as diet). Very often monitored parameter is therefore body fat (BF).

There are many methods applied to the evaluation of body composition that can be classified as reference and non-reference. According to Heyward and Wagner (2004) the reference methods ("gold standard") are underwater weighting, air-displacement plethysmography and dual-energy X-ray absorptiometry (DEXA). These methods are used for the evaluation of the validity of other (non-reference) methods. Since the reference methods are demanding for equipment as well as implementation of measurement, they are mainly used in medicine. In practice, non-reference methods are used most frequently: these are field methods (standardized anthropometry, methods based on bioelectrical impedance analysis) that allow examining larger sample groups in the field, are less demanding for instrumentation and also are affordable. There have already been many studies that compare the final values 
of the body composition parameters acquired by various methods. There have been comparisons of results measured by the DEXA method (and other laboratory methods), anthropometric methods as well as the bioelectrical impedance method (BIA). The studies state both the found differences in the final values of the measured parameters and the validity of the applied methods to laboratory methods (Beeson et al., 2010; Dolezal, Lau, Abrazado, Storer, \& Cooper, 2013; Gába, Kapuš, Cuberek, \& Botek, 2015; Gupta, Balasekaran, Victor, Hwa, \& Shun, 2011; Leahy, O’Neill, Sohun, \& Jakeman, 2012; Mojtahedi, Valentine, \& Evans 2009; Rutherford, Diemer, \& Scott 2011).

At present, however, the portfolio of devices using the BIA method is continuously expanding as a result of the wide use of this method in the field as measurements by this method are fast and staff training is simple and reasonably priced. Nonetheless, the problem is that despite using the same method, bioimpedance analyzers can differ in many parameters. They use different electric current frequencies, a different number of electrodes and the electric current may be conducted through different parts of the body. Another issue is the unavailability of the used equations in the analyzer software and the lack of information about the proband groups from which reference data were taken for the calculation of the final values. It is not possible to calculate any potential differences in the final values when more sophisticated instrumentation or an analyzer by a different producer is acquired. A similar problem may occur when the individual is measured in a different work station. The only way how to encompass such differences is to take such measurements in practice and check any potential differences. The knowledge of any potential differences is essential in case of repeated measurements with the aim to understand changes in body composition that could be caused by ontogenetic changes or external interventions.

The main objective of the study is to compare and evaluate the differences of values of the analysis of the body fat of university students measured by bioimpedance analyzers that differ in the applied electric current frequency, number of electrodes and flow of the electric current through the individual body parts.

\section{Methods}

\section{Participants}

The research group included 130 individuals in total (73 males and 57 females). Three male and two female were removed from the group after outliers. Thus, the final number of monitored individuals was 125 (70 males and 55 females). The basic characteristic of the study sample is presented in the Results part in Table 1. None of the participants had any medical issues; they did not take any medicine or food supplements. They participated in the research voluntarily and they were informed about the process of the research in advance. Also, they signed informed consent with the participation in the research. The research was approved by the Ethical Board of the University of Ostrava and it is in compliance with the Helsinki Declaration. The males were university students studying physical education and sports. Therefore, we can call them a specific population group and the acquired results may be applied to athletes of a whole range of sports disciplines that will show similar values of the monitored parameters (e.g. body fat representation which is a very frequently monitored parameter in sports). The females were university students of fields that did not focus on sports. Therefore, we can apply their results on the general population of women without any medical problems.

\section{Procedures}

The participants of the measurements were informed of the conditions they had to observe prior to measurement in advance (no alcohol consumption for 24 hours prior to measurement, no vigorous exercise less than 12 hours prior to measurement, no food and beverages 3 hours prior to measurement, urination immediately before measurement; only women that did not have their menstrual period were measured).

Measurements took place in the morning (7.30 a.m.-9.00 a.m.) on the same day in the week. All principles of measurement defined in the operating instructions for the individual analyzers were met. The participants attended all measurements wearing underwear. The measurement was executed standing, always by the same team of researchers who have several years of experience with such measurements. The body fat of each participant was successively measured on all applied BIA analyzers in the following order: Tanita 418 MA ( SFBIA $_{4}$ ), InBody 720 (MFBIA $\left.{ }_{4720}\right)$, InBody R20 (MFBIA ${ }_{4-\mathrm{R} 20}$ ), Omron BF 300 (SFBIA ${ }_{2}$ ). To exclude any potential influence of the final measured value due to delays between measurements (e.g. by consumption of food or liquids), the individual measurements were executed in immediate succession and the participants were under continuous supervision. The total body water (TBW), which is a primarily measured parameter when the BIA method is used, was also measured. TBW values are not stated for the SFBIA analyzer because the output of this analyzer does not specify the value. The body height, which is an input parameter for measurements by the used analyzers, was measured using the A-226 anthropometer (Trystom, Olomouc, Czech Republic). The body weight as 
an input parameter for the Omron BF 300 analyzer, which is not a scale, was taken by the Tanita BC 587 digital scale (Tanita Corporation, Tokyo, Japan).

The used analyzers for the body composition diagnostics and their basic characteristics:

- Tanita 418 MA (Tanita Corporation, Tokyo, Japan) is a tetrapolar single-frequency BIA analyzer that uses the electric current frequency of $50 \mathrm{kHz}$ for measurement. Eight point touch electrodes are used for measurement. The analyzer is also a digital scale.

- InBody 720 (Biospace, Seoul, Korea) is a tetrapolar multi-frequency BIA analyzer that uses the gradual electric current frequency of 1, 5, 50, 250, 500 and $1000 \mathrm{kHz}$ for measurement. Eight point touch electrodes are used for measurement. The analyzer is also a digital scale.

- InBody R20 (Biospace, Seoul, Korea) is a tetrapolar multi-frequency BIA analyzer that uses the electric current frequency of 20 and $100 \mathrm{kHz}$ for measurement. Eight point touch electrodes are used for measurement. The analyzer is also a digital scale.

- Omron BF 300 (Omron Corporation, Tokyo, Japan) is a bipolar single-frequency BIA analyzer (hand-hand) that uses the electric current frequency of $50 \mathrm{kHz}$ for measurement.

\section{Statistical processing}

The results were statistically processed using the IBM SPSS Statistics (Version 21; IBM, Armonk, NY, USA). Remote observations were identified by box plots and the normality of distribution was verified by the Shapiro-Wilk test. With regard to the normal distribution of values, we used the paired samples t-test to verify the statistical significance of the differences of the results between the individual devices. The statistical significance level was determined to be $\alpha=.05$ for all tests used.

In values where statistically significant differences were found, we used the effect size to assess practical significance (Cohen, 1988). Recommendations for Cohen's $d: 0.2=$ minor change, $0.5=$ medium change, $0.8=$ major change. The value of Cohen's $d \geq 0.5$ was considered to be a practically significant difference.

To express the level of correlation between the results of measurement by the individual analyzers for the body fat, we used Pearson correlation coefficient (Westgard, 2008). To evaluate the homogeneity of the results between two analyzers, we also used the BlandAltman's analysis (Bland \& Altman, 2010).

\section{Results}

The basic characteristics of the monitored group and the $\mathrm{BF}$ value measured by the individual analyzers are presented in Table 1 and 2.

The differences in the values of the measured $\mathrm{BF}$ and TBW representation by the used analyzers and the results of their statistical analyses are presented in Table 3 and 4.

Table 1

Characteristics of the monitored group

\begin{tabular}{ccccccc}
\hline & \multicolumn{2}{c}{ Males $(n=70)$} & & \multicolumn{2}{c}{ Females $(n=55)$} \\
\cline { 2 - 3 } \cline { 5 - 6 } & $M$ & $S D$ & & $M$ & $S D$ \\
\hline Age (years) & 20.2 & 1.1 & & 19.8 & 1.2 \\
Height (cm) & 180.8 & 5.9 & & 166.6 & 6.0 \\
Weight (kg) & & & & & \\
SFBIA & 75.1 & 7.4 & & 59.2 & 5.9 \\
MFBIA $_{4-720}$ & 75.1 & 7.7 & & 59.4 & 5.8 \\
MFBIA $_{4-\text { R20 }}$ & 75.2 & 7.4 & & 59.3 & 5.9 \\
${\text { BMI }\left(\mathrm{kg} / \mathrm{m}^{2}\right)}^{2}$ & 23.0 & 1.6 & & 21.4 & 1.8 \\
\hline
\end{tabular}

Note. $\mathrm{BMI}=$ body mass index, $\mathrm{SFBIA}_{4}=$ Tanita $\mathrm{BC} 418 \mathrm{MA}$, MFBIA $_{4-720}=$ InBody 720, MFBIA 4 -R20 $=$ InBody R20

Table 2

Values of the body fat and total body water

\begin{tabular}{|c|c|c|c|c|}
\hline & \multicolumn{2}{|c|}{ Males $(n=70)$} & \multicolumn{2}{|c|}{ Females $(n=55)$} \\
\hline & $M$ & $S D$ & $M$ & $S D$ \\
\hline \multicolumn{5}{|l|}{$\mathrm{BF}(\%)$} \\
\hline $\mathrm{SFBIA}_{4}$ & 10.6 & 4.0 & 24.2 & 4.1 \\
\hline MFBIA $_{4720}$ & 10.6 & 4.0 & 23.6 & 5.1 \\
\hline MFBIA $_{4 \mathrm{R} 20}$ & 13.2 & 4.0 & 25.2 & 5.0 \\
\hline SFBIA $_{2}$ & 9.6 & 3.3 & 19.0 & 3.9 \\
\hline \multicolumn{5}{|l|}{$\mathrm{BF}(\mathrm{kg})$} \\
\hline $\mathrm{SFBIA}_{4}$ & 8.0 & 3.3 & 14.3 & 3.4 \\
\hline MFBIA $_{4-720}$ & 8.0 & 3.4 & 14.0 & 3.5 \\
\hline MFBIA $_{4-\mathrm{R} 20}$ & 9.9 & 3.4 & 15.0 & 3.3 \\
\hline SFBIA $_{2}$ & 7.2 & 3.0 & 11.3 & 3.0 \\
\hline \multicolumn{5}{|l|}{ TBW (\%) } \\
\hline $\mathrm{SFBIA}_{4}$ & 65.4 & 2.9 & 55.2 & 2.9 \\
\hline MFBIA $_{4720}$ & 65.6 & 3.0 & 55.7 & 3.9 \\
\hline MFBIA $_{4-\mathrm{R} 20}$ & 64.0 & 2.9 & 55.1 & 3.7 \\
\hline \multicolumn{5}{|l|}{ TBW (kg) } \\
\hline $\mathrm{SFBIA}_{4}$ & 49.1 & 4.5 & 32.7 & 2.6 \\
\hline MFBIA $_{4-720}$ & 49.3 & 4.8 & 33.1 & 3.7 \\
\hline MFBIA $_{4-\mathrm{R} 20}$ & 48.1 & 4.7 & 32.7 & 3.7 \\
\hline
\end{tabular}

Note. $\mathrm{BF}=$ body fat, $\mathrm{TBW}=$ total body water, $\mathrm{SFBIA}_{4}=$ Tanita BC 418 MA, MFBIA $_{4-720}=$ InBody 720, MFBIA $_{4 \mathrm{R} 20}=\operatorname{InBody}$ R20, SFBIA $_{2}=$ Omron BF 300. 
Table 3

Differences in measured values - males $(n=70)$

\begin{tabular}{|c|c|c|c|c|}
\hline & Diff & $r$ & $d$ & $95 \%$ LoA \\
\hline \multicolumn{5}{|c|}{ SFBIA $_{4}$ vs. MFBIA 4720} \\
\hline BF (\%) & 0.0 & .68 & - & $(-6.3,6.3)$ \\
\hline $\mathrm{BF}(\mathrm{kg})$ & 0.0 & .75 & - & $(-4.8,4.8)$ \\
\hline TBW (\%) & -0.2 & .65 & - & $(-5.0,4.6)$ \\
\hline TBW (kg) & -0.2 & .93 & - & $(-3.6,3.2)$ \\
\hline \multicolumn{5}{|c|}{ SFBIA $_{4}$ vs. MFBIA } \\
\hline BF (\%) & $-2.6^{* * *}$ & .67 & 0.6 & $(-9.1,3.9)$ \\
\hline $\mathrm{BF}(\mathrm{kg})$ & $-1.9^{* * *}$ & .75 & 0.5 & $(-6.7,2.9)$ \\
\hline TBW (\%) & $1.4^{* * *}$ & .63 & 0.5 & $(-3.5,6.3)$ \\
\hline TBW $(\mathrm{kg})$ & $1.0^{* * *}$ & .93 & 0.2 & $(-2.4,4.4)$ \\
\hline \multicolumn{5}{|c|}{ MFBIA $_{4720}$ vs. MFBIA $_{4 \text { - } 20}$} \\
\hline BF (\%) & $-2.6^{* * *}$ & .81 & 0.6 & $(-7.4,2.2)$ \\
\hline $\mathrm{BF}(\mathrm{kg})$ & $-1.9^{* * *}$ & .84 & 0.5 & $(-5.7,1.9)$ \\
\hline TBW (\%) & $1.6^{* * *}$ & .79 & 0.5 & $(-2.1,5.3)$ \\
\hline TBW $(\mathrm{kg})$ & $1.2^{* * *}$ & .95 & 0.3 & $(-4.1,1.7)$ \\
\hline \multicolumn{5}{|c|}{$\mathrm{SFBIA}_{4}$ vs. SFBIA } \\
\hline $\mathrm{BF}(\%)$ & $1.0^{* *}$ & .77 & 0.2 & $(-4.0,6.0)$ \\
\hline $\mathrm{BF}(\mathrm{kg})$ & $0.8^{* *}$ & .82 & 0.1 & $(-3.1,4.7)$ \\
\hline \multicolumn{5}{|c|}{ MFBIA $_{4720}$ vs. SFBIA 2} \\
\hline $\mathrm{BF}(\%)$ & $1.0^{* *}$ & .66 & 0.2 & $(-5.0,7.0)$ \\
\hline $\mathrm{BF}(\mathrm{kg})$ & $0.8^{* *}$ & .72 & 0.1 & $(-3.9,5.5)$ \\
\hline \multicolumn{5}{|c|}{ MFBIA $_{4 \mathrm{R} 20}$ vs. SFBIA } \\
\hline $\mathrm{BF}(\%)$ & $3.6^{* * *}$ & .64 & 0.9 & $(-2.6,9.8)$ \\
\hline $\mathrm{BF}(\mathrm{kg})$ & $2.7 * * *$ & .72 & 0.7 & $(-2.2,7.4)$ \\
\hline
\end{tabular}

Note. $\quad$ Diff $=$ difference, $r=$ Pearson correlation coefficient,$d=$ effect size, $95 \% \mathrm{LoA}=95 \%$ limits

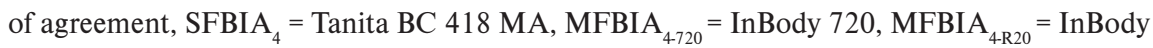
$\mathrm{R}^{20}, \mathrm{SFBIA}_{2}=$ Omron BF 300. ${ }^{* *} p<.001, * * * p<.0001$.

There was no significant difference in the measured results only between the analyzers $\mathrm{SFBIA}_{4}$ and MFBIA $_{4720}$. In other cases, the final significance values ranged from $p<.001$ to $p<.0001$. As for results with significant differences, medium practical significance was found between the results of $\mathrm{SFBIA}_{4}$ and MFBIA $_{4 \mathrm{R} 20}\left(\mathrm{BF} \%, \mathrm{~kg}\right.$ and TBW \%), MFBIA ${ }_{4720}$ and MFBIA $_{4 \mathrm{R} 20}(\mathrm{BF} \%, \mathrm{~kg}$ and TBW \%) and MFBIA 4 -R20 and $\mathrm{SFBIA}_{2}(\mathrm{BF} \%, \mathrm{~kg})(d=0.5-0.7)$ and high practical significance only between MFBIA $_{4-20}$ and SFBIA in the values expressed in percentage $(d=0.9)$. Practical significance between the analyzers $\mathrm{SFBIA}_{4}$ and MFBIA $_{4 \mathrm{R} 20}(\mathrm{TBW} \mathrm{kg})$, MFBIA $_{4720}$ vs. MFBIA ${ }_{4 \mathrm{R} 20}$ (TBW kg), SFBIA $_{4}-$ SFBIA $_{2}$ and MFBIA $_{4720}$ and SFBIA $_{2}$ was not shown in spite of significant differences $(d=0.1-0.3)$. The closeness of results between the individual analyzers expressed in kilograms can be considered to be high, up to very high (Westgard, 2008). The values of Pearson's correlation coefficient $r$ explain $51-90 \%$ of variability. In values expressed in percentage, there is a high closeness of results only between the values of the analyzers MFBIA $_{4720}$ and MFBIA $_{4 \text { R20 }}$ and SFBIA $_{4}$ and SFBIA 2 . The $r$ values explain $59-65 \%$ of variability. The closeness of results between other analyzers is considerable (Westgard, 2008). The $r$ values explain $41-46 \%$ of variability.

Similarly to the men, there was no significant difference in the measured values between $\mathrm{SFBIA}_{4}$ and MFBIA $_{4-720}$; moreover, the female group also did not show any significant difference in the values between $\mathrm{SFBIA}_{4}$ and MFBIA 4 R20 $($ except BF \%). In other cases, the significance ranged from $p<.05$ to $p=.0001$. In spite of the significant difference in the results of SFBIA $_{4}$ and MFBIA $_{4-220}$ (BF \%), MFBIA ${ }_{4720}$ and MFBIA $_{4 \mathrm{R} 20}(\mathrm{BF} \%, \mathrm{~kg}$ and TBW \%, $\mathrm{kg}$ ), practical significance was not shown $(d=0.1-0.3)$. The practical significance in other cases was always high $(d \geq 0.8)$. The values of the Pearson's correlation coefficient $r$ show higher correlations between the results measured by the used analyzers than in men. The closeness of 
Table 4

Differences in measured values - females $(n=55)$

\begin{tabular}{|c|c|c|c|c|}
\hline & Diff & $r$ & $d$ & $95 \%$ LoA \\
\hline \multicolumn{5}{|c|}{$\mathrm{SFBIA}_{4}$ vs. MFBIA 4720} \\
\hline $\mathrm{BF}(\%)$ & 0.6 & .75 & - & $(-6.4,7.6)$ \\
\hline $\mathrm{BF}(\mathrm{kg})$ & 0.3 & .82 & - & $(-4.6,4.0)$ \\
\hline TBW (\%) & -0.5 & .71 & - & $(-6.0,5.0)$ \\
\hline TBW $(\mathrm{kg})$ & -0.4 & .94 & - & $(-3.6,2.8)$ \\
\hline \multicolumn{5}{|c|}{$\mathrm{SFBIA}_{4}$ vs. MFBIA 4 R2 20} \\
\hline BF (\%) & $-1.0^{*}$ & .71 & 0.2 & $(-6.0,8.0)$ \\
\hline $\mathrm{BF}(\mathrm{kg})$ & -0.7 & .81 & - & $(-4.9,3.5)$ \\
\hline TBW (\%) & 0.1 & .72 & - & $(-4.8,5.0)$ \\
\hline TBW $(\mathrm{kg})$ & 0.0 & .95 & - & $(-3.0,3.0)$ \\
\hline \multicolumn{5}{|c|}{ MFBIA $_{4720}$ vs. MFBIA 4 सR20 } \\
\hline $\mathrm{BF}(\%)$ & $-1.6^{* * *}$ & .94 & 0.3 & $(-5.1,1.9)$ \\
\hline $\mathrm{BF}(\mathrm{kg})$ & $-1.0^{* * * *}$ & .95 & 0.2 & $(-3.1,1.1)$ \\
\hline TBW (\%) & $0.6^{* *}$ & .90 & 0.2 & $(-2.8,4.0)$ \\
\hline $\mathrm{TBW}(\mathrm{kg})$ & $0.4^{* *}$ & .97 & 0.1 & $(-1.4,2.2)$ \\
\hline \multicolumn{5}{|c|}{ SFBIA $_{4}$ vs. SFBIA } \\
\hline $\mathrm{BF}(\%)$ & $5.2^{* * *}$ & .82 & 1.3 & $(-9.9,-0.5)$ \\
\hline $\mathrm{BF}(\mathrm{kg})$ & $3.0^{* * *}$ & .89 & 1.0 & $(0.0,6.0)$ \\
\hline \multicolumn{5}{|c|}{ MFBIA $_{4720}$ vs. SFBIA 2} \\
\hline $\mathrm{BF}(\%)$ & $4.6^{* * *}$ & .74 & 1.0 & $(-2.2,11.4)$ \\
\hline $\mathrm{BF}(\mathrm{kg})$ & $2.7^{* * *}$ & .82 & 0.8 & $(-1.3,6.7)$ \\
\hline \multicolumn{5}{|c|}{ MFBIA $_{4 \mathrm{R} 20}$ vs. SFBIA 2} \\
\hline $\mathrm{BF}(\%)$ & $6.2^{* * *}$ & .74 & 1.4 & $(-0.1,12.5)$ \\
\hline $\mathrm{BF}(\mathrm{kg})$ & $3.7^{* * *}$ & .84 & 1.1 & $(0.2,7.2)$ \\
\hline
\end{tabular}

Note. $\quad$ Diff $=$ difference, $r=$ Pearson correlation coefficient, $d=$ effect size, $95 \%$ LoA $=95 \%$ limits of agreement, $\mathrm{SFBIA}_{4}=$ Tanita BC $418 \mathrm{MA}$ MFBIA $_{4720}=\operatorname{InBody}_{720}, \mathrm{MFBIA}_{4 \mathrm{R} 20}=$ InBody R20, SFBIA $_{2}=$ Omron BF 300. ${ }^{*} p<.05,{ }^{* *} p<.001,{ }^{* * *} p<.0001$.

results is high, up to very high (Westgard, 2008). The $r$ values between analyzers SFBIA $_{4}$ and MFBIA $_{4720}$ (TBW kg), SFBIA 4 and MFBIA $_{4-\mathrm{R} 20}$ (TBW kg), and MFBIA $_{4720}$ and MFBIA $_{4 \mathrm{R} 20}(\mathrm{BF}, \mathrm{TBW} \%$ and $\mathrm{kg}$ ) explain $81-94 \%$ of variability. In other cases, the values range from 50 to $79 \%$.

The results of the Bland-Altman's analysis of BF representation (a primarily monitored parameter in this study) are illustrated in the form of Bland-Altman's plots (Figures 1 and 2). The plots present the differences found in $\mathrm{BF}$ values expressed in percentage, measured by two different analyzers. The plots show that for the male group, the smallest differences in the mean are between analyzers MFBIA $_{4720}$ and SFBIA $_{4}$ where the mean is almost zero $($ mean $=0.6)$. In women, there were differences between MFBIA $_{4720}$ and SFBIA $_{4}$ and MFBIA ${ }_{4-\mathrm{R} 20}$ and SFBIA $_{4}($ mean $=-3.5$ and 3.6). However, according to the $95 \%$ interval of agreement, there are large differences in the individual persons among the analyzers, which are manifested by the wide interval of agreement. To assess the size of the values measured by the individual analyzers, we can use the assessment of mean displacement (the Mean axis) in the plots. The displacement of the mean axis downwards means that the results measured by the second analyzer are higher than the results measured by the first analyzers. The displacement of the mean axis upwards means that the results measured by the first analyzer are higher than the results measured by the second analyzer. As an example of the mean displacement downwards, in the male group we provide a comparison between $\mathrm{MFBA}_{4720}$ and $\mathrm{MFBIA}_{4 \mathrm{R} 20}$ $($ mean $=-24.4)$ where MFBIA $_{4-20}$ measures considerably higher values. As an example of the mean displacement upwards, in the male group we provide a comparison between MFBIA ${ }_{4 \mathrm{R} 20}$ and $\mathrm{SFBIA}_{2}($ mean $=32.6)$ where MFBIA $_{4-\mathrm{R} 20}$ also measured considerably higher values. The relative differences in the measured values in the individual participants are mostly concentrated around the mean relative difference in the values of 

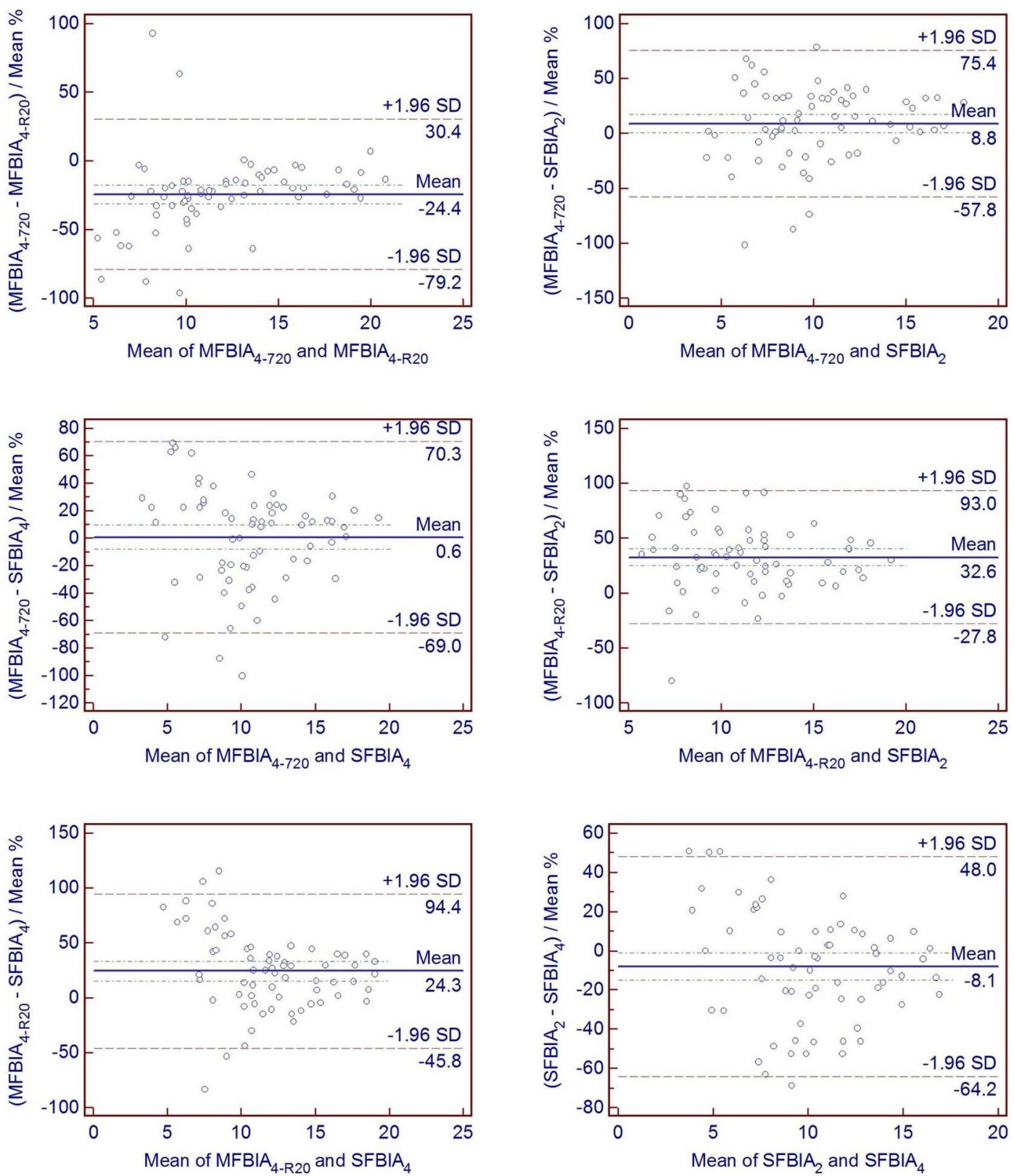

Figure 1. Bland-Altman plots with 95\% limits of agreement and correlation analysis of the differences between the body fat values measured by the used analyzers in percentage - males

the two analyzers MFBIA $_{4720}$ and MFBIA ${ }_{4 \mathrm{R} 20}$ which is also reflected in the values of the Pearson's correlation coefficient $r$ (Tables 3 and 4). It is thus obvious that these two analyzers provide the most predictable results. The analyzers have one manufacturer and therefore they should have the same software for the calculation of BF.

\section{Discussion}

The study used BIA analyzers that use different frequencies for the measurement, with electric current going through different body parts. The objective of the study was not to evaluate their validity against the reference method as many studies dealing with this issue have already been published. For the InBody analyzers, the correlation with the DEXA reference method was determined to be at the level of .94-.96; the study included healthy men and women by the age of 18 (Karelis, Chamberland, Aubertin-Leheudre, \& Duval, 2013). Even though they used a different analyzer than we did in this study, we can assume that the InBody analyzers we used will have similar correlations as they are made by the same manufacturer and use the same frequencies, number of electrodes as well as the method of conducting current through the human 

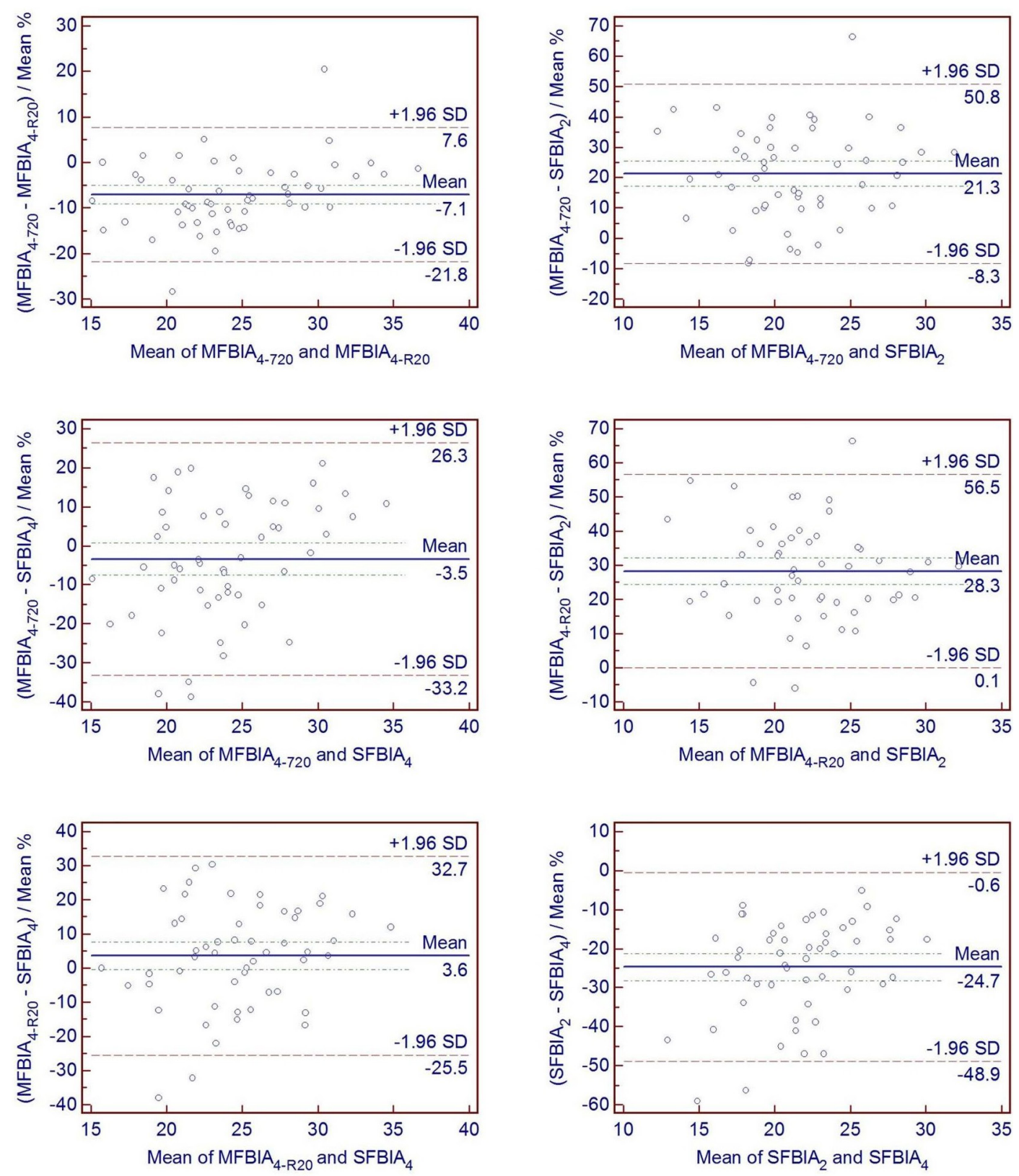

Figure 2. Bland-Altman plots with $95 \%$ limits of agreement and correlation analysis of the differences between the body fat values measured by the used analyzers in percentage - females

body for the measurement. As for the single-frequency analyzer $\mathrm{SFBIA}_{4}$, the value of correlation to the DEXA method found in physical education students was .82-.84 in relation to the used measuring mode (Kutáć, Gajda, Přidalová, \& Šmajstrla, 2008). As for single frequency bipolar hand-to-hand analyzers, the values of correlation with the DEXA method for the verification of validity in sporting young men and women ranged from .82 to .88 in relation to the used analyzers (Esco, Olson, Williford, Lizana, \& Russell, 2011; Loenneke et al., 2013; Wang et al., 2013). Even though InBody seems to be the most accurate analyzer, other analyzers can also be considered sufficiently accurate as the values of correlation in all the aforementioned studies exceeded .8 which is a high closeness of results (Westgard, 2008). Analyzers with such closeness of results to the reference method may be considered to be sufficiently accurate for the needs of the process of physical education and diagnostics of athletes.

In the males, the lowest differences between the mean values of $\mathrm{BF}$ representation were found between the analyzers $\mathrm{SFBIA}_{4}$ and $\mathrm{MFBIA}_{4720 \text {. }}$ The overall analysis of the differences in the mean values measured by the individual BIA analyzers did not show any dependence that would be related to the used BIA analyzer. The difference in the values measured by the analyzer 
of the same manufacturer, MFBIA $_{4-720}$ and MFBIA $_{4-\mathrm{R} 20}$ was greater than the difference between the single and multi-frequency analyzers MFBIA $_{4720}$ and SFBIA $_{4}$ or


ference between the analyzers MFBIA ${ }_{4-\mathrm{R} 20}$ and SFBIA 2 was the greatest of all comparisons in the male.

The diagnostic practice also needs to respond to the question of the impact of the differences in the results on the interpretation of the measured values. The monitored men were students of physical education. The mean values of the BF representation percentage measured by the BIA method in physical education students that are presented in some professional studies do not exceed 13\% (Kutáč, 2012; Kutáč, Gajda, \& Přidalová, 2009; Kutáč, Přidalová, \& Riegerová, 2008). Therefore, the detailed analysis of the values measured by the individual analyzers also focused on how many participants would correspond with the mean values of physical education students. The limit value was $13 \%$ of body fat. For the SFBIA analyzer it was found that the body fat representation of 18 participants $(25.71 \%)$ did not correspond with the values of physical education students (exceeded 13\%); the number of 20 (28.57\%) for MFBIA $_{4-720}, 31$ (44.28\%) for MFBIA $_{4-\mathrm{R} 20}$ and $13(18.57 \%)$ for SFBIA $_{2}$. The results show that there would be different evaluation of several participants in case of interpretation of the acquired results. There would be a significant difference especially when using MFBIA ${ }_{4-\mathrm{R} 20 \text {. }}$

In the females, similarly to males, the lowest differences in the mean values were found between the analyzers SFBIA $_{4}$ and MFBIA $_{4-720}$. The greatest differences were found between the single frequency BIA hand-to-hand analyzer $\left(\mathrm{SFBIA}_{2}\right)$ and the other analyzers. The SFBIA 2 analyzer measures the lowest values. The found differences were even higher than in the comparison of the measured values by the BIA and DEXA methods (Gupta et al., 2011; Mojtahedi et al., 2009; Kutáč et al., 2008; Trutschnigg et al., 2008). In these studies, the differences did not exceed $2.7 \%$ BF. To assess the impact of the found differences on the interpretation of results in the diagnostic practice, we will use the BF representation at the level of $25 \%$, which is the value stated for young female (Görner, Boraczyński, \& Štihec, 2009; Nazmi, Irfan, Osman, \& Serdar, 2011; Rutherford, Diemer, \& Scott, 2011). The value of $25 \%$ BF representation was exceeded in 25 female (45.45\%) measured by SFBIA, in 16 women (29.09\%) measured by MFBIA ${ }_{4720}$, in 27 (49.09\%) measured by MFBIA $_{4 \mathrm{R} 20}$ and only in $5(9.09 \%)$ measured by SFBIA $_{2}$. There is a noticeable difference that became apparent when the analyzer was changed. The greatest difference would occur with the use of SFBIA ${ }_{2}$.
The differences in the mean values we found that were measured by the used BIA analyzers are lower than differences stated in other studies. The differences in studies that dealt with the comparison of wholebody analyzers with leg-to-leg analyzers reached the mean value of $7.4 \% \mathrm{BF}$, and the value of $6.2 \% \mathrm{BF}$ when compared with hand-to-hand analyzers (Chin, Kiew, \& Girandola, 2006; Trutschnigg et al., 2008).

TBW is the primarily measured parameter in the BIA method, BF values are calculated additionally. The TBW value predicates the status of organism hydration. Professional studies state that when hydration decreases by 2 to $3 \%$, there is a substantial reduction of performance in physical activities (GarcíaJiménez, Lucas, \& García-Pellicer, 2011; Hamouti, Del Coso, Estevez, \& Mora-Rodriguez, 2010; Maughan $\&$ Shirreffs, 2010). A decrease of hydration by 3-5\% causes digestive issues during training and muscle spasms (Beachle \& Earle, 2008; Burke, 2007; Montain, 2008; Oppliger \& Bartok, 2002). From this point of view, we can state that the differences we found in the mean values measured by the individual analyzers are negligible. Even though some differences were statistically significant and the value of Cohen's $d$ showed the medium value of the effect of size, none of the differences exceeded the level of $2 \%$ TBW; the differences ranged from 0 to $1.6 \% \mathrm{TBW}$. As for $\mathrm{BF}$, the differences found were within the difference intentions. However, a more detailed analysis of the differences in the individual participants showed that the difference in the range of $2-3 \%$ TBW was found in $13(18.6 \%)$ males between $\mathrm{SFBIA}_{4}$ and MFBIA ${ }_{4720}$, in $16(22.3 \%)$ males between $\mathrm{SFBIA}_{4}$ and $\mathrm{MFBIA}_{4 \mathrm{R} 20}$, and in 11 (15.7\%) males between MFBIA $_{4-720}$ and MFBIA $_{4-\mathrm{R} 20}$. As for females, there were 11 (20\%) participants between SFBIA $_{4}$ and MFBIA $4.720,15$ (27.3\%) between SFBIA and MFBIA $_{4-\mathrm{R} 20}$, and 6 (10.1\%) between MFBIA $_{4-720}$ and $\mathrm{MFBIA}_{4-\mathrm{R} 20}$. The difference in the range of 3 to $5 \%$ TBW was found in $10(14.3 \%)$ males between SFBIA $_{4}$ and MFBIA $_{4-720}, 19$ (27.1\%) males between SFBIA $_{4}$ and MFBIA $_{4-\mathrm{R} 20}$, and 16 (22.9\%) males between MFBIA $_{4-720}$ and MFBIA $_{4-\mathrm{R} 20}$. In females, the difference was found in 13 (23.6\%) participants between SFBIA $_{4}$ and MFBIA $4.720,11$ (20\%) between SFBIA and MFBIA $_{4-\mathrm{R} 20}$, and 3 (5.5\%) between MFBIA M.720 and MFBIA $_{4-\mathrm{R} 20}$. As the detailed analysis implies, the evaluation of the final values of several participants could be misinterpreted if the analyzers were changed.

\section{Study limitations}

We are aware of the fact that the results we obtained might be influenced by the selected groups. The monitored males are individuals with regular physical activity which they perform in their field of study. These 
individuals are also active athletes at the performance level. Therefore, their results may only apply to the sporting population.

The validity of the results is also limited by the used BIA analyzers. Since there is a wide range of BIA analyzers on the market, the submitted study could be considered a base for including other BIA analyzers, or other population groups in the research.

\section{Conclusions}

Even though the differences between the mean values measured by the used analyzers were low in majority of the cases and ranged at the level of the errors of measurement, a detailed analysis showed substantially higher differences in several participants. Replacing an analyzer with a different one could lead to misinterpretation of the measured values in diagnostics. The differences found during repeated measurements would not need to be a result of an external intervention or the ontogenetic development of the individual; they could be caused by different measuring of the analyzers. The results also showed significant (statistically and practically) differences between analyzers by the same manufacturer, but a different series. It is thus obvious that a high correlation of measured values does not guarantee conformity of results and therefore, it is not recommended to even use different types of analyzers by one producer in practice.

\section{Acknowledgment}

This study was financed by the project no. SGS 6136/ $\mathrm{PdF} / 2013$.

\section{References}

Bauer, P. W., Pivarnik, J. M., Fornetti, W. C., Jallo, J. J., \& Nassar, L. (2005). Cross validation of fat free mass prediction models for elite female gymnasts. Pediatric Exercise Science, 17, 337-344.

Beachle, T. R., \& Earle, R. W. (2008). Essentials of strength training and conditioning. Champaign, IL: Human Kinetics.

Beeson, W. L., Batech, M., Schultz, E., Salto, L., Firek, A., Deleon, M., ... Cordero-MacIntyre, Z. (2010). Comparison of body composition by bioelectrical impedance analysis and dual-energy X-ray absorptiometry in Hispanic diabetics. International Journal of Body Composition Research, $8,45-50$.

Bland, J. M., \& Altman, D. G. (2010). Statistical methods for assessing agreement between two methods of clinical measurement. International Journal of Nursing Studies, 47, 931-936.
Burke, L. (2007). Practical sport nutrition. Champaign, IL: Human Kinetics.

Chin, M. K., Kiew, O. F., \& Girandola, R. N. (2006). A comparison of body fat measurement by BodPod, skinfolds, and three bioelectrical impedance analysis techniques in Chinese college student. International Journal of Physical Education, 43(2), 77-85.

Cohen, J. (1988). Statistical power analysis for the behavioral sciences (2nd ed.). Hillsdale, NJ: Lawrence Erlbaum Associates.

Dolezal, B. A., Lau, M. J., Abrazado, M., Storer, T. W., \& Cooper, C. B. (2013). Validity of two commercial grade bioelectrical impedance analyzers for measurement of body fat percentage. Journal of Exercise Physiology Online, 16(4), 74-83.

Esco, M. R., Olson, M. S., Williford, H. N., Lizana, S. N., \& Russell, A. R. (2011). The accuracy of hand-to-hand bioelectrical impedance analysis in predicting body composition in college-age female athletes. Journal of Strength and Conditioning Research, 25, 1040-1044.

Gába, A., Kapuš, O., Cuberek, R., \& Botek, M. (2015). Comparison of multi- and single-frequency bioelectrical impedance analysis with dual-energy X-ray absorptiometry for assessment of body composition in post-menopausal women: Effects of body mass index and accelerometerdetermined physical activity. Journal of Human Nutrition and Dietetics, 28, 390-400.

García-Jiménez, J. V., Lucas, J. L. Y., \& García-Pellicer, J. J. (2011). Fluid balance and dehydration in futsal players: Goalkeepers vs. field players. International Journal of Sport Science, 7(22), 3-13.

Görner, K., Boraczyński, T., \& Štihec, J. (2009). Physical activity, body mass, body composition and the level of aerobic capacity among young, adult women and men. Sport Scientific \& Practical Aspects, 6(2), 7-14.

Green, M. R., Pivarnik, J. M., Carrier, D. P., \& Womack, C. J. (2006). Relationship between physiological profiles and on-ice performance of a national collegiate athletic association division I Hockey Team. Journal of Strength and Conditioning Research, 20, 43-48.

Gupta, N., Balasekaran, G., Victor, G. V., Hwa, C. Y., \& Shun, L. M. (2011). Comparison of body composition with bioelectric impedance (BIA) and dual energy X-ray absorptiometry (DEXA) among Singapore Chinese. Journal of Science and Medicine in Sport, 14, 33-35.

Hamouti, N., Del Coso, J., Estevez, E., \& Mora-Rodriguez, R. (2010). Dehydration and sodium deficit during indoor practice in elite European male team players. European Journal of Sport Science, 10, 329-336.

Heyward, V. H., \& Wagner, D. R. (2004). Applied body composition assessment. Champaign, IL: Human Kinetics.

Karelis, A. D., Chamberland, G., Aubertin-Leheudre, M., \& Duval, C. (2013). Validation of a portable bioelectrical impedance analyzer for the assessment of body composition. Applied Physiology, Nutrition and Metabolism, 38, 27-32.

Kutáč, P. (2012). Application of typical error of measurement for accuracy of measurement of body composition in athletes using the BIA method. Medicina Sportiva, 16, 150-154. 
Kutáč, P., Gajda, V., \& Přidalová, M. (2009). The body composition of PE teacher. New Educational Review, 19(3-4), 263-272.

Kutáč, P., Gajda, V., Přidalová, M., \& Šmajstrla, V. (2008). Validity of measuring body composition by means of the BIA method. New Medicine, 12, 89-93.

Kutáč, P., Přidalová, M., \& Riegerová, J. (2008). Somatic characteristics of present male and female university students of physical education at various types of universities in the Czech Republic. Slovenská Antropológia, 11(1), 46-56.

Leahy, S., O’Neill, C., Sohun, R., \& Jakeman, P. (2012). A comparison of dual energy X-ray absorptiometry and bioelectrical impedance analysis to measure total and segmental body composition in healthy young adults. European Journal of Applied Physiology, 112, 589-595.

Loenneke, J. P., Wray, M. E., Wilson, J. M., Barnes, J. T., Kearney, M. L., \& Pujol, T. J. (2013). Accuracy of field methods in assessing body fat in collegiate baseball players. Research in Sports Medicine, 21, 286-291.

Maughan, R. J., \& Shirreffs, S. M. (2010). Development of hydration strategies to optimize performance for athletes in high-intensity sports and in sports with repeated intense efforts. Scandinavian Journal of Medicine \& Science in Sports, 20(Suppl. 2), 59-69.

McArdle, W. D., Katch, F. I., \& Katch, V. L. (2007). Exercise physiology. Energy, nutrition, and human performance. Philadelphia, PA: Lippincott Williams \& Wilkins.

Mojtahedi, M. C., Valentine, R. J., \& Evans, E. M. (2009). Body composition assessment in athletes with spinal cord injury: Comparison of field methods with dual-energy X-ray absorptiometry. Spinal Cord, 47, 698-704.

Montain, S. J. (2008). Hydration recommendations for sport 2008. Current Sports Medicine Reports, 7, 187-192.

Nazmi, S., Irfan, Ö., Osman, P., \& Serdar, B. (2011). Evaluation of body fat percentage of female university students according to three different methods. Ovidius University Annals, Series Physical Education \& Sport / Science, Movement \& Health, 11, 244-249.

Oppliger, R. A., \& Bartok, C. (2002). Hydration testing of athletes. Sports Medicine, 32, 959-971.

Parikh, S. J., Edelman, M., Uwaifo, G. I., Freedman, R. J., Semega-Janneh, M., \& Reynolds, J. (2004). The relationship between obesity and serum 1,25-dihydroxy vitamin D concentrations in healthy adults. Journal of Clinical Endocrinology \& Metabolism, 89, 1196-1199.

Pluijm, S. M., Visser, M., Smit, J. H., Popp-Snijders, C., Roos, J. C., \& Lips, P. (2001). Determinants of bone mineral density in older men and women: Body composition as mediator. Journal of Bone and Mineral Research, 16, 2142-2151.

Pravn, P., Cizza, G., Bjarnason, N. H., Thompson, D., Daley, M., Wasnich, R. D., ... Christiansen, C. (1999). Low body mass is an important risk factor for low bone mass and increased bone loss in early postmenopausal women. Journal of Bone and Mineral Research, 14, 1622-1627.

Quinney, H. A., Dewart, R., Game, A., Snydmiller, G., Warburton, D., \& Bell, G. (2008). A 26 year physiological description of a National Hockey League team. Applied Physiology, Nutrition, and Metabolism, 33, 753-760.

Rahimi, R. (2006). Effect of moderate and high intensity weight training on the body composition of overweight men. Facta Universitatis: Series Physical Education and Sport, 4, 93-101.

Rutherford, W. J., Diemer, G. A., \& Scott, E. D. (2011). Comparison of bioelectrical impedance and skinfolds with hydrodensitometry in the assessment of body composition in healthy young adults. Journal of Research in Health, Physical Education, Recreation, Sport, and Dance, 6, 56-60.

Sanchez, M. C., Sanz, D., \& Zabala, M. (2007). Anthropometric characteristics, body composition and somatotype of elite junior tennis players. British Journal of Sports Medicine, 41, 793-799.

Trutschnigg, B., Kilgour, R. D., Reinglas, J., Rosenthall, L., Hornby, L., Morais, J. A., \& Vigano, A. (2008). Precision and reliability of strength (Jamar vs. Biodex handgrip) and body composition (dual-energy X-ray absorptiometry vs. bioimpedance analysis) measurements in advanced cancer patients. Applied Physiology, Nutrition, and Metabolism, 33, 132-140.

Wang, J.-G., Zhang, Y., Chen, H.-E., Li, Y., Cheng, X.-G., $\mathrm{Xu}, \mathrm{L} .$, ... Li, B. (2013). Comparison of two bioelectrical impedance analysis devices with dual energy X-ray absorptiometry and magnetic resonance imaging in the estimation of body composition. Journal of Strength and Conditioning Research, 27, 236-243.

Westgard, J. O. (2008). Basic method validation (3rd ed.). Madison, WI: Westgard QC. 